\title{
Silane and Epoxy Coatings: A Bilayer System to Protect AA2024 Alloy
}

José Ignacio Iribarren-Mateos, ${ }^{\text {a }}$ Irene Buj-Corral, ${ }^{\text {b }}$ Joan Vivancos-Calvet, ${ }^{\text {b }}$ Carlos Alemán, ${ }^{\text {a,c }}$ José Ignacio Iribarren ${ }^{a^{*}}$, Elaine Armelin ${ }^{\text {a,c * }}$

${ }^{a}$ Department of Chemical Engineering, ETSEIB, Universitat Politècnica de Catalunya, Av. Diagonal 647, 08028, Barcelona, Spain.

${ }^{b}$ Department of Mechanical Engineering, ETSEIB, Universitat Politècnica de Catalunya (UPC), Avda. Diagonal 647, Barcelona E-08028, Spain

${ }^{b}$ Centre for Research in Nano-Engineering, Universitat Politècnica de Catalunya, Campus Sud, Edifici C', C/Pasqual i Vila s/n, Barcelona E-08028, Spain

Corresponding Authors: jose.iribarren@upc.edu and elaine.armelin@upc.edu 


\begin{abstract}
This work has proved that a good combination of a simple and fast metal pre-treatment, followed by the deposition of a thin layer of an organic-inorganic silane coating and further layer of epoxy coatings, are able to protect the aluminium alloy AA2024-T3 against corrosion in high concentrations of $\mathrm{NaCl}$ solution. The alloy AA2024 is one of the most employed aluminium alloy in structural applications due to its good mechanical properties. However, AA2024 alloy series commonly presents galvanic corrosion due to the rich content of copper element. The influence of different surface pre-treatments, the presence of a silane layer as pre-coating treatment and the influence of phosphonic acids combined with the silane layer on the corrosion protection and adhesion to the aluminium alloy have been examined using accelerated corrosion tests. High roughness and the presence of a pre-coating film between the metal surface and the organic coating were essential for a good protection and resistance to blistering appearance in the surface of AA2024-T3.
\end{abstract}

Keywords: sol-gel technology; epoxy coatings; silane compounds; aluminium alloy; corrosion assays 


\section{Introduction}

Aluminium alloy AA2024-T3 is a high strength material usually obtained by a rolling based transformation process. Its hardness, improved by means of precipitation process during the cooling, provides an alloy with very interesting applications as structural materials (e.g. fuselage skin in aerospace industry). However, its excellent mechanical properties, which are mainly due to copper content (about 4-5\%), are in contrast with a poor resistance against corrosion. This drawback is consequence of the galvanic coupling between copper and aluminium, which results in microstructural changes based on the segregation of intermetallic compounds into grain boundaries producing intergranular corrosion [1].

Chromic anodizing has been widely used to protect the AA2024-T3 alloy, several inhibitors being incorporated to increase the performance of anodic film formed [2]. However, the use of $\mathrm{Cr}(\mathrm{VI})$ is becoming very problematic due to its classification as carcinogenic to human health and also its contribution to environmental pollution as a toxic residue. Alternative inhibitors are being currently investigated to substitute the $\mathrm{Cr}(\mathrm{VI})$, such as vanadates, molibdates and permanganates based solutions and triazol or thiazol derivatives [3-5].

The development of non-chromate environmentally friendly coatings has been promoted in the last decade. In particular, a considerable effort has been devoted to investigate aluminium surface modification with silane films, which can be applied coupled with organic coatings. Usually, silane coatings are the first layer of the hybrid organic-inorganic barrier in contact with the metal surface, whereas the second layer is an organic resin (e.g. epoxy commercial primers) applied onto the silane coating. Alternatively, silane compounds can also be pre-hydrolyzed to obtain stable polysiloxanes miscible with primers based in polymer resins [6-10]. Surface modification of metals by phosphonic acids and derivatives (e.g. aminotrimethyllenephosphonic acid) is another strategy to replace chromium based pretreatments by formation of self-assembled monolayers through spontaneous or induced adsorption in metal surface [11-13]. Sol-gel technologies commonly use liquid sample deposition combined with curing processes. Furthermore, sol-gel matrices may result in a particular technology that offers many possibilities by, for example, incorporating nanoparticles of ceramic substances (e.g. zirconium dioxide or cerium nitrates) to 
protect metal surfaces, $[14,15]$ as well as to control the viscosity of the hydrolysed silane solution before deposition.

Among silanes for sol-gel depositions, TEOS (tetraethylorthosilicate), VTMS (vinyltrimethoxysilane), VTES (vinyltriethoxysilane), and GPTMS (3glycidoxypropyltrimethoxysilane) have been frequently used in several previous works [16-19]. An interesting review has been published by Wang and Bierwagen regarding sol-gel technology and corrosion protection [20]. The effect of the surface treatment with these silanes in combination with phosphonic acid compounds, such as 1,2$\begin{array}{llll}\text { diaminoethanetetrakis-methylenephosphonic acid } & \text { (EDTPO) }\end{array}$ aminotrimethylenephosphonic acid (ATMP), has been studied for the protection against corrosion of AA2024 aluminium alloy [21-23]. Authors were particularly interested in the influence of different parameters, such as hydrolysis time, temperature and acid concentration, in the silane coating formation and further protective effect. Characterization of these compounds was carried out by means of FTIR and Raman spectroscopies and electrochemical impedance spectroscopy (EIS). Morphological aspects related with the characteristics of films were controlled by means of optical and electron microscopies. The corrosion protection was evaluated through accelerated assays using sodium chloride solutions $\left(0.05 \mathrm{~mol} \mathrm{~L}^{-1}\right)$ and polarization techniques.

The present work attempts to constitute the nexus with these preceding works. Thus, the same sol-gel technology has been used for the deposition of VTMS and TEOS in a solution medium with a very low concentration of an organic phoshonic acid derivative, diethylenetriaminepentakis-methylphosphonic acid (DETAPO). Phosphonic molecules have a positive synergic effect on the formation of thicker silane films, as proved in previous work [23]. Therefore, one of our aims is to test a phosphonic derivative with higher concentration of $\mathrm{O}=\mathrm{P}-\mathrm{OH}$ groups as compared to ATMP or EDTPO molecules. Another important objective is the evaluation of two different pre-treatments to obtain a suitable metal surface, which are intended to guarantee a good adhesion of the silane coating. Thus, the mechanical dealing with ceramic abrasive has been compared with a chemical etching typically applied in anodising technology. The surface state is controlled in both cases by tracing the roughness after the different pre-treatments. Physicochemical, thermal and morphological characterization have been carried out using techniques like FTIR spectroscopy, DSC, TGA, optical and scanning electron microscopy (SEM). Finally, protective properties of the bilayered system, composed by the new silane films and a commercial epoxy primer, have been studied using 
accelerated corrosion assays. Results have been contrasted with a monolayered system composed by the epoxy coating directly adhered to the aluminium surface.

\section{Experimental Section}

\subsection{Materials}

All reagents used were of analytical grade and supplied by Sigma Aldrich. The chemical structure of the two silane derivatives, VTMS $\left(\mathrm{C}_{5} \mathrm{H}_{12} \mathrm{O}_{3} \mathrm{Si}\right)$ and TEOS $\left.\left(\mathrm{Si}\left(\mathrm{OC}_{2} \mathrm{H}_{5}\right)_{4}\right)\right)$, and the phosphonic acid, diethylenetriaminepentakis(methylphosphonic acid) (DETAPO, $\mathrm{C}_{9} \mathrm{H}_{28} \mathrm{~N}_{3} \mathrm{O}_{15} \mathrm{SiP}_{5}$ ), employed in this work are shown in the Scheme 1.

\subsection{Surface pre-treatment}

Disk specimens of aluminium AA2024-T3, with diameter $40 \mathrm{~mm}$ and length 10 $\mathrm{mm}$, were used for the corrosion assays. They were obtained from a rolled bar, which was turned in a conventional lathe in order to obtain the required diameter. Later, the disks were cut in a band saw. Disks were faced in a conventional lathe up to required thickness. Before the silane deposition, two different pre-treatments were applied on the aluminium surface to remove dirt and fat residues and to improve the adhesion of the hybrid material on the metal surface. In the first pre-treatment, some specimens were mechanically polished with corundum 800 [24] as abrasive grain, in an automatic polishing machine Presi Mecapol 230 at a speed of $50 \mathrm{~min}^{-1}$ and with work-piece force on the disk of $1.5 \mathrm{daN}$. This was followed by a wash with distilled water. Hereafter, such specimens have been labelled as "C". The second pre-treatment consisted on a chemical etching with an industrial acid degreaser used in anodising and painting technology to prepare aluminium surfaces (Novaclean ${ }^{\circledR}$ AL 86LF from Henkel Ibérica S.A.). For this purpose, specimens were previously sanded with silicon carbide of different grain size (320, 600 and 1200),[24] cleaning with water and acetone being performed after change each sand paper and also before and after the immersion in Novaclean ${ }^{\circledR}$ AL 86LF. These specimens have been named "N". Finally, all AA2024 specimens were dried with a hot air flow before the silane deposition.

\subsection{Silane film preparation and deposition}

A mixture containing $50 \mathrm{~mL}$ of ethanol, $46 \mathrm{~mL}$ of deionized water, $3 \mathrm{~mL}$ of VTMS

and $1 \mathrm{~mL}$ of TEOS was prepared. Then, $2.3 \mathrm{mg}$ of DETAPO, corresponding to a concentration of $3.75 \times 10^{-5} \mathrm{~mol} \cdot \mathrm{L}^{-1}$, was incorporated, the mixture being stirred 
mechanically for $1 \mathrm{~h}$ at room temperature and subsequently stored for 3 days prior to use. Immediately after the pre-treatment, AA2024 samples were immersed in the sol-gel bath for $30 \mathrm{~min}$ and cured in an oven at $110{ }^{\circ} \mathrm{C}$ for $1 \mathrm{~h}$. The silane film was applied to several specimens previously pretreated with mechanical decaling and chemical etching, as detailed before.

\subsection{Epoxy paint preparation and application}

The primer used as a second coating layer to the protection of the AA2024 surface is a two components epoxy-polyamide material commercialized by Pinturas Hempel S.A. (Hempadur 15570 and curing agent 95570). This primer is characterized by a high performance in protection against corrosion and the dry film paint has good mechanical properties as hardness, toughness and good adherence. The ratio resin-hardener ratio (v/v) used was $4 / 1$ according to the manufacturer recommendations. The mixture was prepared in a polyethylene reservoir at room temperature $\left(25^{\circ} \mathrm{C}\right)$ by stirring for about 30 minutes. The discoid specimens were immersed into the reservoir containing the liquid paint suspended by a nylon thread. This process should be reproducible as much as possible in order to obtain a homogeneous distribution of paint across the surface and comparable thickness in all specimens tested.

The painted specimens were allowed to cure for 7 days at room temperature. Finally, commercial paint Hempadur 15300/15302 was applied to the edges and holes to avoid corrosion preferential beginning. Once the paint was completely dried, thickness was measured by using the meter Mega-Check Pocket of Neurtek S.A. The apparatus was previously calibrated to non-ferrous basis by using the gauges supplied.

\subsection{Characterization techniques}

Roughness measurements. In order to obtain required roughness parameters of chemically and mechanically polished samples, a contact roughness meter TaylorHobson Talysurf series 2 was used. In order to discard a preferred direction of the polishing or etching marks on the sample's surface, both longitudinal and transversal measurements were performed. Roughness parameters that were taken into account are detailed below [25].

Arithmetical mean roughness, $\mathrm{R}_{\mathrm{a}}$, is the arithmetic mean of absolute height values in a roughness profile along a sampling profile. Total roughness height, $\mathrm{R}_{\mathrm{t}}$, is defined as the distance between the highest peak and the lowest valley in a roughness profile. 
Skewness, $\mathrm{R}_{\mathrm{sk}}$, which can take either positive or negative values, measures the symmetry of the profile. Positive values indicate that height of peaks exceeds depth of valleys while negative values indicate that depth of valleys exceeds height of peaks. Kurtosis $R_{k u}$ is related to the sharpness or pointedness of the roughness profile. A kurtosis value of 3 corresponds to a normal height distribution. Higher kurtosis values refer a spiked height distribution, while lower kurtosis values reflect a squashed height distribution [26].

Parameters of the Abbott-Firestone curve or bearing area curve are also reported in the present stud [27]. The curve is obtained from a roughness profile by drawing lines that are parallel to the datum and measuring the percentage of material that lies within the profile. Total height of the curve is divided into three parts, corresponding to parameters $R_{p k}, R_{k}$ and $R_{v k}$. Parameter $R_{p k}$ is related to height of peaks above the central part of the profile or core, or the highest part of the surface which can be worn because of friction with another surface; parameter $R_{k}$ with the profile core; and parameter $R_{v k}$ with the depth of valleys below the profile core, or the lowest part of the surface which favours the physical fixation of a coating layer on the workpiece's surface.

FTIR spectroscopy. The silane modified films preparation was monitored by FTIR spectroscopy. Structural characterization of the starting materials used to obtain silane compounds and tracing the curing process were performed using a Nicolet 6700 FTIR spectrometer equipped with a Smart SAGA (specular aperture grazing angle) accessory and Omnic software. Films were directly deposited on aluminium surface. Spectra were collected with an incidence angle of $80^{\circ}$ from the normal surface using a wavenumber range of 4000-600 $\mathrm{cm}^{-1}$ at a resolution of $8 \mathrm{~cm}^{-1}$.

Thermal analysis. Differential scanning calorimetry (DSC) and thermogravimetric analysis (TGA) were used in thermal characterization of the silane coatings. DSC was performed using a TA Instruments Q100 series equipped with a refrigerated cooling system (RCS) operating at temperatures from $-90{ }^{\circ} \mathrm{C}$ to $200{ }^{\circ} \mathrm{C}$. Experiments were conducted under a flow of dry nitrogen with a sample weight of approximately $5 \mathrm{mg}$ and calibration was performed with indium. On the other hand, TGA was carried out with a Q50 thermogravimetric analyzer of TA Instruments at a heating rate of $10^{\circ} \mathrm{C} / \mathrm{min}$ under nitrogen atmosphere and a temperature range from $20^{\circ} \mathrm{C}$ to $600{ }^{\circ} \mathrm{C}$.

Microscopy analysis. The effects of the different pre-treatments on the aluminium surface were observed using an Olympus BX-51 light polarizing microscope operating in reflection mode with an Olympus C3030Z digital camera coupled. The silane and 
epoxy deposition, as well as the corrosion products obtained after the corrosion assays, were later examined using scanning electron microscopy (SEM). SEM studies were carried out using a Focused Ion Beam Zeiss Neon40 scanning electron microscope equipped with an energy dispersive X-ray (EDX) spectroscopy system and operating at $30 \mathrm{kV}$. Samples were mounted on a double-sided adhesive carbon disc and sputtercoated with a thin layer of carbon to prevent sample charging problems. Photographs and micrographs of the specimens were taken before exposure to the aggressive medium as well as through-out the corrosion assays.

\subsection{Accelerated corrosion assays.}

The main purpose of accelerated corrosion tests was to evaluate the surface state evolution versus time of the aluminium AA2024T3 pieces coated with organicinorganic silane and epoxy paint. Simultaneously, the assay has enabled to study the comparative behaviour of aluminium alloy coated with epoxy primer (only one coat) and the differences between the mechanical dealing and chemical etching after two layers depositions (i.e. silane as inner layer and epoxy as outer layer).

Corrosion studies were carried out using home-made equipment developed and patented in our laboratory [28] for cyclic test in an aggressive solution. The aggressive medium was an aqueous solution of $\mathrm{NaCl}(3.5 \mathrm{wt} . \%, \mathrm{pH}=6.6)$ stored in a glass container at room temperature. The operating controlled program conditions for one cycle were: immersion of coated steel sheets $(15 \mathrm{~min})$, wring out (30 min), drying stage with bulbs $(230 \mathrm{~V}-100 \mathrm{~W}, 10 \mathrm{~min})$ and cooling time at room temperature $(5 \mathrm{~min})$. Painted panels were sealed on the edges and around the hole used for securing the pieces. The samples were scribed and tested for a total exposure time of 45 days (corresponding to 1080 cycles of 1 hour each one). After $1080 \mathrm{~h}$, corrosion performance was evaluated by ASTM D1654 [29] and with SEM photographs of corrosion products. The dry film thickness (DFT) of the coating varied of $90 \pm 15 \mu \mathrm{m}$ for all samples.

2.7. Adhesion of coatings. The adhesion strength of coatings on AA2024 discs was determined by pull-off test (UNE-EN-ISO 4624) using KN-10 Neurtek S.A. adhesion equipment (dollies: $20 \mathrm{~mm}$ diameter) [30]. The adhesion measurements were performed prior to exposure in $3.5 \mathrm{wt} \% \mathrm{NaCl}$ solution (dry adhesion) and after 5, 10, 30 and 45 days of immersion at room temperature (wet adhesion). For each system, two areas were examined and those with the interfacial failure were considered and the minimum force to detach the coatings from substrate was recorded accordingly. 


\section{Results and Discussion}

\subsection{Surface characterization}

One of our aims is to evaluate the influence of pre-treatments in the subsequent deposition of silane coating. Pre-treatment may influence the roughness of aluminium surface, which is a factor responsible for silane deposition. Therefore, the first parameter to be evaluated is the surface of disk aluminium specimens, either after chemical pickling process with Novaclean ${ }^{\circledR}$ AL 86LF or after mechanical polishing with corundum 800, as described in the Experimental Section.

Table 1 shows average values of roughness parameters for $\mathrm{N}$ and $\mathrm{C}$ specimens, which were measured considering 5 pairs of directions, where each pair was constituted by a given direction (longitudinal) and a direction perpendicular to it (transversal).

$R_{a}$ and $R_{k}$ parameters are very similar for both specimens, showing similar average heights of roughness profiles and a similar height of the core section of the profile. $R_{t}$ is slightly higher for specimen $\mathrm{N}$ than for specimen $\mathrm{C}$, showing a higher distance between the highest peak and the lowest valley when Novaclean ${ }^{\circledR}$ AL 86LF is used. This is illustrated in Figure 1a for a sampling length of $2 \mathrm{~mm}$. As it can be seen, the highest peak for specimen $\mathrm{C}$ is above the highest peak for specimen $\mathrm{N}$ while the lowest valley for specimen $\mathrm{N}$ is below the lowest valley for specimen $\mathrm{C}$.

Parameter $R_{s k}$, which is related with the symmetry of the roughness profile, is slightly positive and negative for specimen $\mathrm{C}$ and $\mathrm{N}$, respectively. It can be concluded that for the mechanically treated specimen $\mathrm{C}$ average height of peaks is higher than average depth of valleys, indicating a surface in which peaks are most prominent than valleys. On the contrary, for the specimen treated with Novaclean average depth of valleys is higher than average height for peaks. This corresponds to a surface with more prominent valleys than peaks.

Parameter $\mathrm{R}_{\mathrm{ku}}$, which shows the sharpness of the roughness profile, is higher than 3 for the two specimens studied. This means that both profiles are spiked. Furthermore, the profile of the chemically etched specimen $\mathrm{N}$ is sharper than that of the mechanically polished specimen $\mathrm{C}$.

Finally, $\mathrm{R}_{\mathrm{pk}}$ shows a higher value for specimen $\mathrm{C}$ than for specimen $\mathrm{N}$. For this reason, peaks are more important in specimen $C$ than in specimen N. Regarding to $R_{v k}$, 
values are higher for specimen $\mathrm{N}$ than for specimen $\mathrm{C}$. This means that valleys are more important for specimen $\mathrm{N}$ than for specimen $\mathrm{C}$, which is consistent with $\mathrm{R}_{\mathrm{sk}}$ observations, providing a wider area for physical fixation of coatings.

Figure $1 \mathrm{~b}$ presents Abbott-Firestone curves of one measurement for specimen $\mathrm{C}$ and one measurement for specimen $\mathrm{N}$, both in the transversal direction. Only one measuring direction was taken into account, since marks on the chemically or mechanically polished surface did not present a preferred direction. In order to compare both curves $90 \%$ of material was taken as reference, as it is usual in the study of cylinders wear for internal combustion engines [31]. Both curves show the S-shape that is typical for abrasive machining processes. Although both curves are very similar, meaning that surfaces where the coating will adhere are similar, it can be concluded that specimen $\mathrm{C}$ has higher peaks than specimen $\mathrm{N}$, while specimen $\mathrm{N}$ has deeper valleys.

The main conclusion is that surfaces obtained by mechanical polishing with corundum 800 and with Novaclean ${ }^{\circledR}$ AL $86 \mathrm{LF}$ present very similar roughness parameters. However, parameters $R_{\mathrm{sk}}, \mathrm{R}_{\mathrm{pk}}$ and $\mathrm{R}_{\mathrm{vk}}$ show that valleys height exceeds peaks height in surfaces obtained with Novaclean ${ }^{\circledR}$ AL 86LF. Therefore, valleys provide a higher entlocking area for adhesion of the silane coating when chemical etching with Novaclean ${ }^{\circledR}$ AL $86 \mathrm{LF}$ is used than when mechanical polishing with corundum is performed. For this reason, attending only to mechanical entlocking, coating is predicted to present slightly higher adhesion on the specimen treated with Novaclean ${ }^{\circledR}$ AL 86LF than on the specimen treated with corundum 800.

\subsection{Silane characterization}

FTIR spectra of monomers VTMS, TEOS, hydrolyzed TEOS and DETAPO are shown in Figure 2. VTMS spectrum (Figure 2a) exhibits the characteristic C-H stretching bands at 3026, $2940 \mathrm{~cm}^{-1}$ and 2840 while those at 1597 and $1408 \mathrm{~cm}^{-1}$ associated to non-conjugate $\mathrm{C}=\mathrm{C}$ bond. Particular remarkable are the absorptions at $1010-1200 \mathrm{~cm}^{-1}$, which correspond to the stretching of $\mathrm{Si}-\mathrm{O}-\mathrm{C}$ bond. Peaks from methoxy groups $\left(2841 \mathrm{~cm}^{-1}\right.$ and $\left.1450 \mathrm{~cm}^{-1}\right)$ are frequently used to follow the progress of the reaction between VTMS and TEOS, as well as the disappearance of $\mathrm{C}=\mathrm{C}$ bands. In TEOS monomer C-H stretching bands are present between 2880 and $2980 \mathrm{~cm}^{-1}$, very strong and sharp peaks being also observed at 1100-1200 $\mathrm{cm}^{-1}$ (Si-O-C) (Figure 2b). After hydrolysis (Figure 2c), the main changes in the spectrum correspond to the presence of $\mathrm{Si}-\mathrm{OH}$ bands at 3500 and $950 \mathrm{~cm}^{-1}$ and strong and broad peak associated to 
$\mathrm{Si}-\mathrm{O}-\mathrm{Si}$ at 1058 and $750 \mathrm{~cm}^{-1}$. The presence of water is evidenced at 3100 and 1614 $\mathrm{cm}^{-1}$.

Organic-inorganic self-assembled monolayers between aluminium alloy phosphonic molecules have been extensively studied and proved for many authors. Therefore, we intended to use a phosphonic derivative with many $\mathrm{O}=\mathrm{P}-\mathrm{OH}$ groups to promote the TEOS-VTMS network deposition. As it can be seen in Figure 2d, the DETAPO spectrum shows lower resolution, which is consequence of a high density of hydrogen bond linkages among phosphonic groups. A broad and strong peak from $\mathrm{P}-\mathrm{OH}$ stretching, forming hydrogen bonds, is observed at $3700-3050 \mathrm{~cm}^{-1}$. Furthermore, C-H stretching from $\mathrm{CH}_{2}$ groups, with worse resolution than in VTMS and TEOS spectra, is identified at about $2900 \mathrm{~cm}^{-1}$, and $\mathrm{O}=\mathrm{P}-\mathrm{OH}$ groups are detected by the stretching absorption band at $1930-1540 \mathrm{~cm}^{-1}$. On the other hand, the presence of hydrogen bonds is also detected around $900-1200 \mathrm{~cm}^{-1}$ due to the bending of ether linkages between $\mathrm{P}-$ $\mathrm{O}-\mathrm{H} \cdots \mathrm{O}=\mathrm{P}-\mathrm{C}$ groups. Detection of $\mathrm{N}-\mathrm{C}$ stretching was difficult because of the overlap with $\mathrm{O}=\mathrm{P}-\mathrm{OH}$ absorption bands.

Finally, the FTIR spectrum of the coating formed by VTMS-TEOS-DETAPO, conveniently cured, was recorded adhered to the aluminium surface (Figure 3). As it can be seen, absorption bands corresponding to $\mathrm{C}=\mathrm{C}$ bonds $\left(1596\right.$ and $1408 \mathrm{~cm}^{-1}$ ), gradually disappear and new peaks appear. Si-O-Si linkages are mainly observed at 775, 883, 1080 and $1168 \mathrm{~cm}^{-1}$, the latter being overlapped with $\mathrm{P}-\mathrm{O}-\mathrm{Al}$ stretching absorptions. Due to the low thickness of the films, the presence of noise in the $3600-3400 \mathrm{~cm}^{-1}$ region makes difficult the detection of the absorption bands from silanol groups ( $\mathrm{Si}-$ $\mathrm{OH})$ typically formed at the outer layer. Accordingly, the FTIR spectrum confirms the cross-linked structure of the hybrid silane coating, even though the identification of $\mathrm{P}-$ $\mathrm{O}-\mathrm{Al}$ and $\mathrm{Si}-\mathrm{OH}$ groups is problematic due to both overlap of bands and noise problems.

Thermal analysis of VTMS-TEOS-DETAPO solid film was carried out. The DSC curve proves the presence of highly amorphous phase corresponding to a vitreous material (Figure 4a). The thermogram only shows one glass transition at $42^{\circ} \mathrm{C}$ in the second heating, which indicates that the material is completely crosslinked after the first heating. On the other hand, the TGA curve (Figure 4b) exhibits a very low weight loss $(\sim 10 \%)$ at $800^{\circ} \mathrm{C}$, with three mainly decays at 132,444 and $760^{\circ} \mathrm{C}$, according to the derivative weight change versus temperature. Thus, the silane coating obtained is a vitreous and brittle film mainly formed by an inorganic network, despite a small organic 
content from organophosphonic groups is present. Therefore, it justifies the need of a second barrier organic layer for further protection of the aluminium surface and to preserve the mechanical integrity of the silane film.

\subsection{Accelerated corrosion assays: adhesion and corrosion from scribe}

The next step, previous to evaluation of resistance against corrosion, was the deposition of epoxy primer over the silane coating. The anticorrosive paint was applied by immersion and the thickness of coatings was measured in both specimen faces in 5 different points. The average thickness of epoxy coating was described in the Experimental Section. The organic coating thickness is a very important parameter since it can be correlated with the adherence and corrosion resistance of the coating acting as a barrier. In general, high thicknesses result in a poor adherence and, therefore, a low corrosion resistance. Accordingly, aluminium disks coated with similar epoxy thickness were selected for assays. In order to evaluate the blistering formation or film detach between the interfaces metal-silane coating and silane-epoxy coating, all samples were scratched with a knife type blade, corrosion progress being evaluated around the scribe.

Corrosion accelerated tests were carried out in sodium chloride aqueous solution $(\mathrm{NaCl} 3.5 \% \mathrm{w} / \mathrm{w})$ in accordance with the cyclic sequence previously explained in the Experimental Section. Five extractions of coated discs, corresponding to 5, 10, 20, 30 and 45 days, were carried out to evaluate the temporal evolution of the resistance against corrosion. Photographs of specimens before and after 30 days of corrosion exposure are shown in the Figure 5a and 5b, respectively. Apparently, all coatings are well adhered. However, results along the time proved that silane films acts as a good adherence promoter between the epoxy primer and the aluminium surface, as will be evidenced below.

After 45 days, the epoxy painted over the VTMS-TEOS-DETAPO coating resists to detach, either in samples pretreated with mechanical polishing or with chemical etching, whereas samples without silane coating present several blistering around the scratch. The well-known phenomenon of blistering is clearly appreciated for specimens without silane film in Figure $5 \mathrm{~b}(\mathrm{EI} 0-\mathrm{N}-2 \mathrm{~A})$, whereas this effect is lower in specimens containing silane film previously treated with mechanically scaling (EI 1-C-9B). It should be noted that specimens containing silane film and previously treated with chemical etching (EI 1-N-2A) do not show blistering appearance and, therefore, their corrosion protective characteristics are qualitatively better than those of specimens 
without previous treatment and with mechanical treatment. A possible explanation for this behaviour is that Novaclean ${ }^{\circledR}$ AL 86LF promotes the oxide formation and selective dissolution of intermetallic alloys $\mathrm{Al}-\mathrm{Cu}$, avoiding the microstructural galvanic corrosion. On the other hand, in spite of the catalytic concentration of phosphonic groups $\left(3.75 \times 10^{-5} \mathrm{~mol} \cdot \mathrm{L}^{-1}\right)$, this compound promote the adhesion by covalent bond between silane film and aluminium. Some authors reported the negative effect on the adhesion when proportions higher than the critical micelle concentration (CMC) of phosphonic compound are used [32-33].

Figure $5 \mathrm{c}$ shows high magnification micrographs of the scribe zone. As it can be seen, high degree of corrosion can be appreciated, in specimens not treated with silane, which has been attributed to the presence of copper and iron oxides (red-brown colour precipitates) observed in the blistering areas around the scribe. These specimens were considered as the control of reference in the corrosion tests. The specimens treated mechanically before of the silane deposition show a white oxide tightly bonded to the metal surface, such oxides being not observed in the control specimens. Regarding to specimens with chemical etching (micrograph not shown), a similar behaviour was observed. The chemical nature of this white precipitate, only observed in the aluminium samples with an intermediate thin silane layer, was checked by EDX analysis (discussed below). This precipitate, insoluble in deionised water at $40{ }^{\circ} \mathrm{C}$, has been associated to the formation of an aluminium oxide protective layer instead of copper-iron aggressive oxides observed on the control specimen.

Finally, some morphological characteristics were studied by SEM. Figure 6 compares surface and cross-section representative micrographs for uncoated AA2024, AA2024/silane and AA2024/silane/epoxy. Figure 6a allows appreciate some marks on AA2024 sample from the mechanical pre-treatment with corindon 800 , which mainly involve $\mathrm{Al}, \mathrm{Cu}, \mathrm{Mg}, \mathrm{Mn}$ and $\mathrm{Fe}$ elements as is reflected in the corresponding EDX analysis (Figure 6b). After the VTMS-TEOS-DETAPO deposition (Figure 6c), these marks are smoothed and the EDX analysis proves the existence of a high concentration of Si with decreasing in $\mathrm{Al}$ concentration (Figure 6d). This feature indicates that the surface is well covered.

As the roughness of aluminium surface is similar for both pre-treatments, we assumed similar thicknesses for the silane coating of all samples and, therefore, the epoxy coating thickness is not expected to be influenced by such factor (i.e. results with and without silane can be directly compared). Samples were cut and slightly polished to 
look at the interface between aluminium and epoxy coating. The thickness of the silane layer was within the nanometric scale and, therefore, its identification in the interface detected by SEM between metal surface and epoxy coating was problematic. Figure 6e shows the cross-section for the sample without silane coating, which suggests that the organic coating is not well adhered. Indeed, many fissures are observed between the organic layer and the metal surface (Figure 6f). On the other hand, samples coated with VTMS-TEOS-DETAPO network shows good film formation to the metal surface (Figure 6g-h), explaining the lowest blistering formation detected for this sample. Samples mechanically polished and coated with silane films presented similar adhesion that samples chemically pickling (micrographs not shown). Thus, good interaction and compatibility between the silane film and the epoxy primer were obtained in both cases.

The corrosion products formed in the scratch were also evaluated using SEM and EDX analyses. As mentioned above, copper and iron oxides uniformly distributed through the aluminium surface were identified in sampled without silane coatings (Figures 7a-b). The composition of the oxide products were evaluated by EDX, as shown in the Figure 7c. Additionally, aluminium is also detected due to the high voltage applied and due to fissures observed at the oxides surfaces. Nevertheless, samples pretreated with Novaclean or corindon and further protected with a silane coating, mainly show big aggregates of $\mathrm{Al}_{2} \mathrm{O}_{3}$ or $\mathrm{AlO}(\mathrm{OH})$ (Figures 7d-e). The EDX analyses (Figure 7f) consistently detect abundance of $\mathrm{Al}, \mathrm{O}$ and $\mathrm{C}$ elements, even though a low concentration of Si can also be occasionally detected in areas where the oxide thickness is thin. Finally, samples mechanically polished with corindon (Figure $7 \mathrm{~g}-\mathrm{h}$ ) present both adhered and brittle aluminium oxides over the scratch, which is responsible in part of the protection observed along time (results discussed below). The elemental composition of the oxides in this sample is similar to that of chemical etching samples (Figure 7i).

Figure 8a plots the corrosion degree versus time for the three examined samples. In control specimens (EI 0-N) the failure area gradually increases from $5^{\text {th }}$ to $45^{\text {th }}$ days. In the chemically treated specimens (EI 1-N), the increment of corrosion products from the $5^{\text {th }}$ day is lower than in the control, the behaviour being also asymptotic until the end of test. Mechanically treated specimens (EI 1-C) show a similar behaviour to that of chemical cleaned specimens, even though the failure is slightly larger for the former than for the latter. Accordingly, the resistance against chloride ions should be considered as very satisfactory, especially for the silane-containing specimens. 
On the other hand, the pull-off test does not produce adhesive failure across the entire interface, either for the samples pre-coated with silane (EI-1-N and EI-1-C) or samples without silane (EI-0-N), pointing to an appropriate adhesion of pre- and topcoats to the metal substrate. Values of adhesion strength obtained are shown in Table 2.

The adhesion degradation was aggressive enough to have a measurable effect of adhesion reduction after 45 days, as expected. In this way, EI-0-N shows a weaker adhesion to aluminium substrate compared to EI-1-N and EI-1-C discs (Figure 8b) after 45 days of corrosion assays. Despite we analysed only two areas for each sample it is interesting to note that there is a slight drop in the adhesion strength from dry state to wet in 5 days for samples with silane pre-coating, whereas sample without silane presents a rise. It is probably due to the rapid ingress of water, and therefore, oxygen in the metal surface causing the formation of a very thin aluminium oxide adherent layer. As the oxide layer grows, the paint film is losing adherence, which does not occur when the intermediate layer is a strong covalent bonding with VTMS-TEOS and phosphonic groups to the metal surface.

Therefore, the results showed that pre-coatings employing VTMS-TEOS-DETAPO very thin films improve the adhesion strength of epoxy primer on AA2024-T3.

\section{Conclusions}

The main conclusions of this work can be summarized as follow:

1. The silane coating (VTMS-TEOS), suitably modified with phosphonic groups (DETAPO), shows good adhesion to metallic substrate as well as good adherence with the epoxy outer layer, which result in an improved corrosion resistance.

2. The silane derivative preparation allows knowing in detail the complexity in solgel deposition technique, since the thickness and curing process is strongly dependent on factors like silane dilution in hydrolysis step, evaporation rate of solvents, temperature and curing time of silane film, as well as the chemical composition and phosphonic derivative concentration.

3. Accelerated corrosion assays show better results with the employment of bilayer systems (silane and epoxy), which is evidenced by the lower blistering compared with control samples based in monolayer system (epoxy). 
4. The comparison of two different surface pre-treatments allows concluding that, with similar roughness, both chemical pre-treatment and mechanical polishing yield a longer protection. This is mainly due to the good covalently bonded $\mathrm{Si}-$ $\mathrm{O}-\mathrm{Al}$ and $\mathrm{P}-\mathrm{O}-\mathrm{Al}$ linkages achieved with the well cleaned aluminium surface. An alternative explanation to the good silane adhesion is the elimination of the intermetallic precipitates (Al- $\mathrm{Cu}-\mathrm{Mn})$ from the AA2024 surface. Therefore, both pre-treatments allow avoid the microstructural galvanic corrosion in this alloy.

5. The presence of a very thin layer of silane coating is essential for the good deposition of the epoxy primer, which acts as a barrier coating to the penetration of chloride ions avoiding, therefore, the pitting phenomenon under the coating.

\section{Acknowledgements}

This work has been supported by MICINN and FEDER funds (MAT2012-34498) and by the DIUE of the Generalitat de Catalunya (2009SGR925). C. A. acknowledges the Generalitat de Catalunya for support his research with the prize "ICREA Academia" for excellence in research. The authors thank Dr. Trifon Trifonov (CRnE-UPC) for the SEM images and Dr. Lourdes Franco for calorimetric data.

\section{References}

[1] M. Iannuzzi, G. S. Frankel, Mechanisms of corrosion inhibition of AA2024-T3 by vanadates. Corros. Sci. 49 (2007) 2371-2391.

[2] V. Mourtalier, M. P. Gigandet, L. Ricq, J. Pagetti, Electrochemical characterization of anodic oxidation films formed in presence of corrosion inhibitors. Appl. Surf. Sci. 183 (2001) 1-9.

[3] X. Li, S. Deng, H. Fu, Sodium molybdate as a corrosion inhibitor for aluminium in $\mathrm{H}_{3} \mathrm{PO}_{4}$ solution. Corrosion Science 53 (2011) 2748-2753.

[4] M. L. Zheludkevich, K. A. Yasakau, S. K. Poznyak, M. G. S. Ferreira. Triazole and thiazole derivatives as corrosion inhibitors for AA2024 aluminium alloy. Corrosion Science 47 (2005) 3368-3383.

[5] C. M. Abreu, M. J. Cristóbal, R. Figueroa, G. Pena, Influence of molybdenum ion implantation on the localized corrosion resistance of a high strength aluminium alloy. Corros. Sci. 54 (2012) 143-152. 
[6] W-G Ji, J.-M. Hu, L. Liu, J.-Q. Zhang, C.-N. Cao, Improving the corrosion performance of epoxy coatings by chemical modification with silane monomers. Surf. Coat. Techn. 201 (2007) 4789-4795.

[7] L. Téllez, F. Rubio, R. Peña-Alonso, J. Rubio, Seguimiento por espectroscopia infrarroja (FT-IR) de la copolimerización de TEOS (tetraetilortosilicato) y PDMS (polidimetilsiloxano) en presencia de tbt (tetrabutiltitanio). Bol. Soc. Esp. Ceram. V. 43 (2004) 883-890.

[8] D. M. Bechi, M. A. de Luca, M. Martinelli, S. Mitidieri, Organic-inorganic coatings based on epoxidized castor oil with APTES/TIP and TEOS/TIP. Prog. Org. Coat. 76 (2013) 736-742.

[9] B. Naderi Zand, M. Mahdavian, Corrosion and adhesion study of polyurethane coating on silane pretreated aluminium. Surf. Coat. Techn. 203 (2009) 1677-1681.

[10] J. B. Bajat, V. B. Miškovíc-Stankovíc, Z. Kacarevíc-Popovíc, Corrosion stability of epoxy coatings on aluminium pretreated by vinyltriethoxysilane. Corros. Sci. 50 (2008) 2078-2084.

[11] A. Raman, M. Dubey, I. Gouzman, E. S. Gawalt. Formation of Self-Assembled Monolayers of Alkylphosphonic Acid on the Native Oxide Surface of SS316L. Langmuir 22 (2006) 6469-6472.

[12] M. Giza, P. Thissen, G. Grundmeier, Adsorption Kinetics of Organophosphonic Acids on Plasma-Modified Oxide-Covered Aluminium Surfaces. Langmuir 24 (2008) 8688-8694.

[13] P. H. Mutin, G. Guerrero, A. Vioux, Hybrid materials from organophosphorus coupling molecules. J. Mater. Chem. 15 (2005) 3761-3768.

[14] E. A. Matter, S. Kozhukharov, M. Machkova, V. Kozhukharov, Comparison between the inhibition efficiencies of $\mathrm{Ce}$ (III) and $\mathrm{Ce}$ (IV) ammonium nitrates against corrosion of AA2024 aluminium alloy in solutions of low chloride concentration. Corros. Sci. 62 (2012) 22-33.

[15] M. L. Zheludkevich, R. Serra, M. F. Montemor, K. A. Yasakau, I. M. Miranda Salvado, M. G. S. Ferreira, Nanostructured sol-gel coatings doped with cerium nitrate as pre-treatments for AA2024-T3. Corrosion protection performance. Electrochim. Acta 51 (2005) 208-217.

[16] A. Conde, A. Durán, J. J. de Damborenea, Polymeric sol-gel coatings as protective layers of aluminium alloys. Prog. .Org. Coat. 46 (2003) 288-296. 
[17] B. Naderi Zand, M. Mahdavian, Evaluation of the effect of vinyltrimethoxysilane on corrosion resistance and adhesion strength of epoxy coated AA1050. Electrochim. Acta 52 (2007) 6438-6442.

[18] H. Yim, M. S. Kent, D. R. Tallant, M. J. Garcia, J. Majewski, Hygrothermal Degradation of (3-Glycidoxypropyl)trimethoxysilane Films Studied by Neutron and Xray Reflectivity and Attenuated Total Reflection Infrared Spectroscopy. Langmuir 21 (2005) 4382-4392.

[19] Z. Feng, Y. Liu, G. E. Thompson, P. Skeldon, Crack-Free Sol-gel Coatings for Protection of AA1050 Aluminium Alloy. Surf. Interf. Anal. 42 (2010) 306-310.

[20] D. Wang, G. P. Bierwagen, Sol-gel coatings on metals for corrosion protection. Prog. Org. Coat. 64 (2009) 327-338.

[21] V. Dalmoro, J. H. Z. dos Santos, D. S. Azambuja, Corrosion behavior of AA2024T3 alloy treated with phosphonate-containing TEOS. J Solid State Electrochem. 16 (2012) 403-414.

[22] V. Dalmoro, J. H. Z. dos Santos, E. Armelin, C. Alemán, D. S. Azambuja, Phosphonic acid/silica-based films: A potential treatment for corrosion protection. Corros. Sci. 60 (2012) 173-180.

[23] V. Dalmoro, J. H. Z. dos Santos, E. Armelin, C. Alemán, D. S. Azambuja, A synergistic combination of tetraethylorthosilicate and multiphosphonic acid offers excellent corrosion protection to AA1100 aluminium alloy. Appl. Surf. Sci. 273 (2013) 758-768.

[24] UAMA B74.10-2010. American National Standards Specifications for Grading of Abrasive Microgrits (2010) 1-2.

[25] ISO 4287:1997. Geometrical Product Specifications (GPS) - Surface texture: Profile method -Terms, definitions and surface texture parameters (1997), 1-25.

[26] D. J. Whitehouse. Handbook of Surface and Nanometrology, Second Edition. CRC Press, (2011) 1-976.

[27] ISO 13565-2:1996. Geometrical Product Specifications (GPS) - Surface texture: Profile method; Surfaces having stratified functional properties - Part 2: Height characterization using the linear material ratio curve, (1996) 1-6.

[28] C. Alemán, E. Armelin, F. Liesa, ES Patent No. P200502713, 2005.

[29] ASTM-1654-05. Standard test method for evaluation of painted or coated specimens subjected to corrosive environments, (2005) 1-4.

[30] UNE-EN ISO 4624. Paints and varnishes - Pull-off test for adhesion. (2003) 1-19. 
[31] R. Kumar, B. Prakash, A. Sethuramiah, A systematic methodology to characterize the running-in and steady-state wear processes. Wear 252 (2002) 445-453.

[32] B. R. A. Neves, M. E. Salmon, P. E. Russell, E. B. Troughton Jr., Spread Coating of OPA on Mica: From Multilayers to Self-Assembled Monolayers. Langmuir 17 (2001) 8193-8198.

[33] E. L. Hanson, J. Schwartz, B. Nickel, N. Koch, M. F. Danisman, Bonding SelfAssembled Compact Organophosphonate Monolayers to the Native Surface of Silicon. J. Am. Chem. Soc. 125 (2003) 16074-16080. 


\section{Captions to Figures}

Figure 1. (a) Roughness profiles for specimens $\mathrm{C}$ and $\mathrm{N}$ in the transversal direction. (b) Abbott-Firestone curves for specimens $\mathrm{C}$ and $\mathrm{N}$ in the transversal direction.

Figure 2. FTIR spectra of: (a) VTMS, (b) TEOS (before hydrolysis), (c) TEOS (after hydrolysis) and (d) DETAPO.

Figure 3. FTIR spectra of the VTMS-TEOS-DETAPO cured film deposited on the AA2024 pretreated surface.

Figure 4. Thermal analyses of the cured films VTMS-TEOS-DETAPO: (a) DSC and (b) TGA.

Figure 5. Optical images of the aluminium disks painted with the commercial epoxy coating and subjected to accelerated corrosion assays: (a) before immersion and (b) after 30 days in $\mathrm{NaCl} 3.5 \%$ solution. (c) High magnifications of corroded areas. Sample labels: EI 0-N-2A (chemical pickling + epoxy primer), EI 1-C-9B (mechanical polishing + VTMS-TEOS-DETAPO film + epoxy primer) and EI 1-N-2A (chemical pickling + VTMS-TEOS-DETAPO film + epoxy primer). Scale bar: (a) and (b) = $10 \mathrm{~mm}$.

Figure 6. (a) SEM micrograph and (b) EDX analysis of AA2024 surfaces; (c) SEM micrograph and (d) EDX analysis of AA2024 coated with a very thin film of VTMSTEOS-DETAPO; (e) low and (f) high magnifications of a cross section of AA22024 coated with the epoxy primer; (g) low and (h) high magnifications of a cross-section of AA2024 pretreated with Novaclean Al 86F, followed by silane and epoxy coatings.

Figure 7. SEM micrographs and EDX analyses of corrosion products observed over scratches at: (a-b-c) AA2024 coated with the epoxy primer; (d-e-f) AA2024 pretreated with Novaclean Al 86F, followed by silane and epoxy coatings; (g-h-i) AA2024 chemically polished with corindon 800 , followed by silane and epoxy coatings.

Figure 8. (a) Progress of corrosion area from scribe vs. time of immersion in $\mathrm{NaCl}$ solution, (b) Adhesion strength vs. time of immersion in $\mathrm{NaCl}$ solution. Inset photographs show examples of disk specimens of aluminium AA2024-T3 after adhesion tests. 
Table 1. Average values of the roughness parameters described in the experimental section for the two specimens analyzed.

\begin{tabular}{cccccccc}
\hline $\begin{array}{c}\text { Pre- } \\
\text { treatment }\end{array}$ & $\begin{array}{c}\mathbf{R}_{\mathbf{a}} \\
(\boldsymbol{\mu \mathbf { m } )}\end{array}$ & $\begin{array}{c}\mathbf{R}_{\mathbf{t}} \\
(\boldsymbol{\mu} \mathbf{m})\end{array}$ & $\mathbf{R}_{\mathbf{s k}}$ & $\mathbf{R}_{\mathbf{k u}}$ & $\begin{array}{c}\mathbf{R}_{\mathbf{k}} \\
(\boldsymbol{\mu m})\end{array}$ & $\begin{array}{c}\mathbf{R}_{\mathbf{p k}} \\
(\boldsymbol{\mu} \mathbf{m})\end{array}$ & $\begin{array}{c}\mathbf{R}_{\mathbf{v k}} \\
(\boldsymbol{\mu m})\end{array}$ \\
\hline $\mathbf{C}$ & 0,202 & 2,012 & 0,371 & 3,844 & 0,635 & 0,339 & 0,249 \\
$\mathbf{N}$ & 0,190 & 2,123 & $-0,443$ & 4,304 & 0,584 & 0,197 & 0,339 \\
\hline
\end{tabular}

Table 2. Adhesion strength of AA2024 coated discs after accelerated corrosion assays in 3.5 wt. $\%$ of $\mathrm{NaCl}$ solution.

\begin{tabular}{ccccccc}
\hline Sample & $\begin{array}{c}\text { 0 days } \\
(\mathbf{M P a})\end{array}$ & $\begin{array}{c}\text { 5 days } \\
(\mathbf{M P a})\end{array}$ & $\begin{array}{c}\text { 10 days } \\
(\mathbf{M P a})\end{array}$ & $\begin{array}{c}\text { 30 days } \\
\mathbf{( M P a})\end{array}$ & $\begin{array}{c}\text { 45 days } \\
(\mathbf{M P a})\end{array}$ & $\begin{array}{c}\text { Adhesion } \\
\text { reduction }\end{array}$ \\
\hline EI-0-N & 2.56 & 3.31 & 2.75 & 1.24 & 0.96 & $62.5 \%$ \\
EI-1-C & 5.93 & 5.37 & 5.62 & 4.21 & 3.87 & $52.9 \%$ \\
EI-1-N & 7.24 & 5.31 & 4.81 & 4.56 & 3.41 & $34.7 \%$ \\
\hline
\end{tabular}




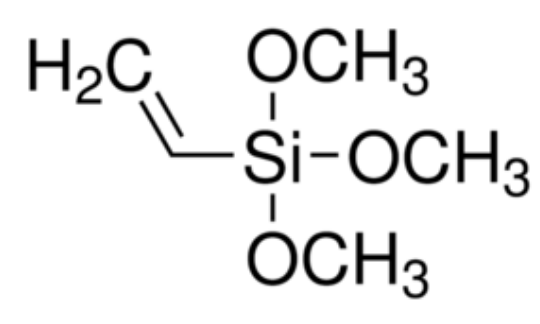

(a)

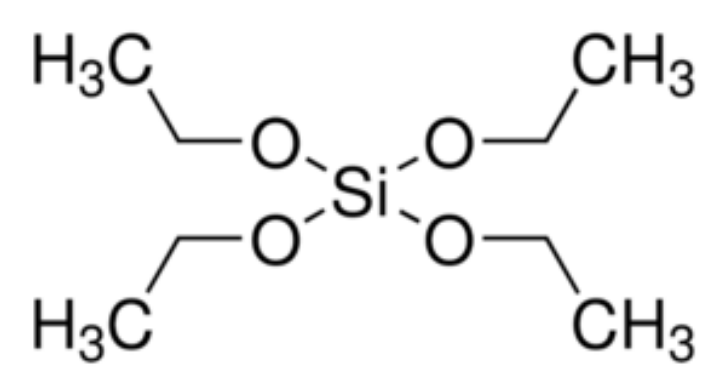

(b)

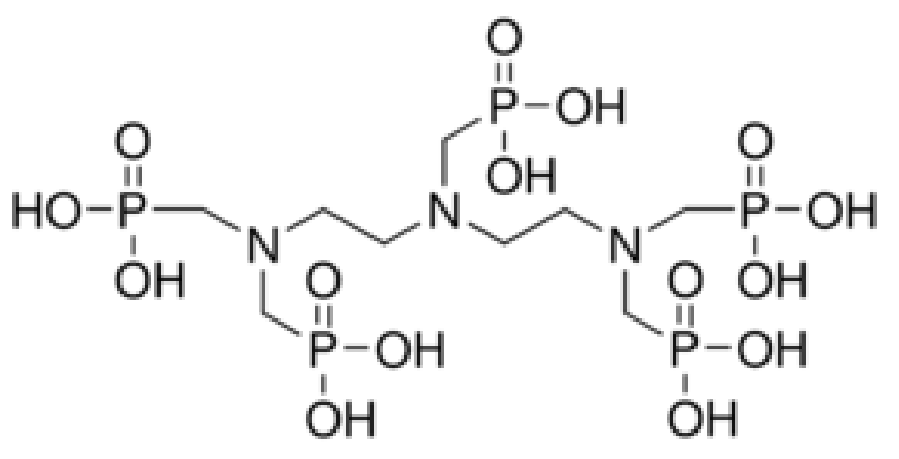

(c)

Scheme 1. Chemical structures of silane derivatives and phosphonic compound used in this work: a) VTMS; b) TEOS; c) DETAPO. 

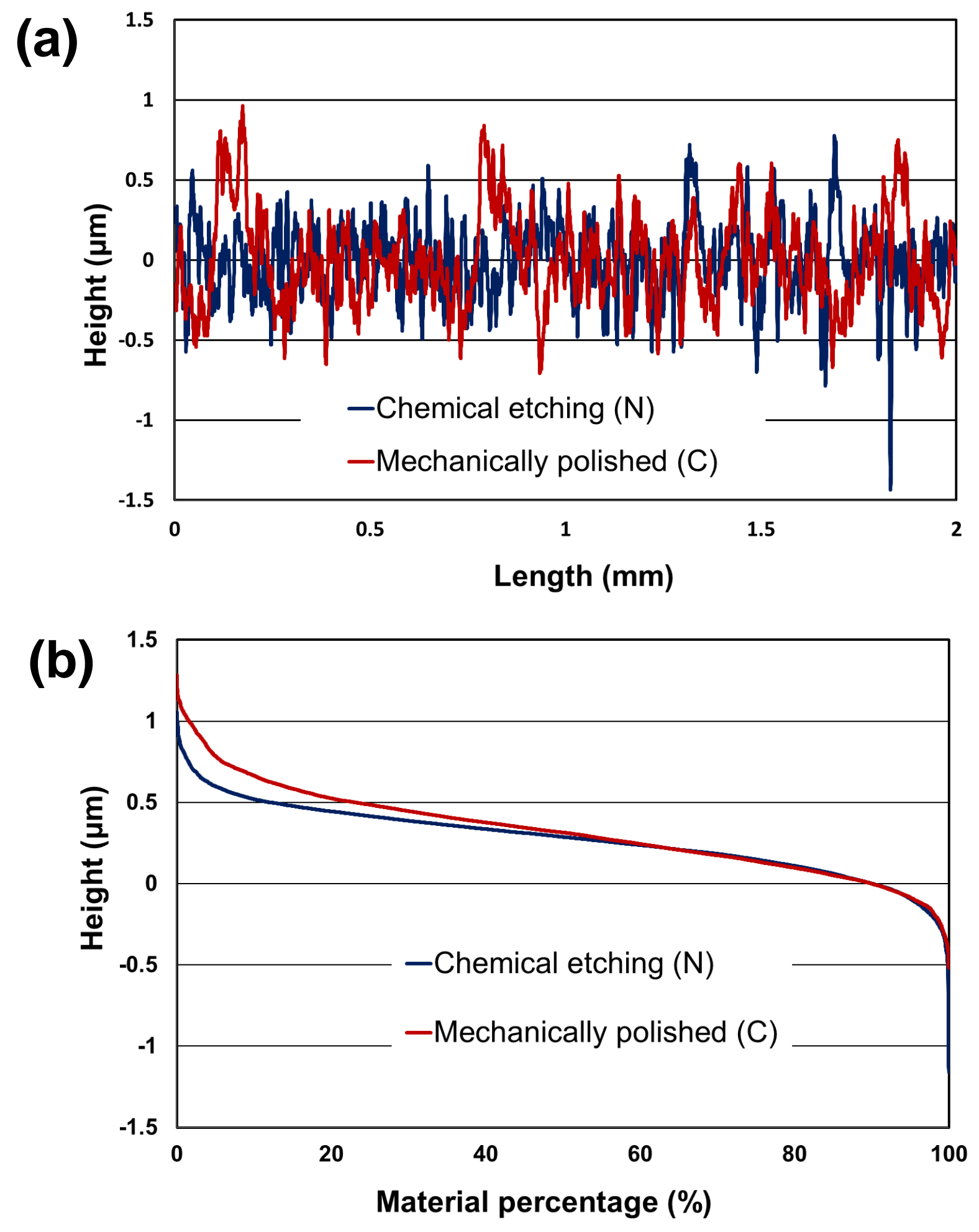

Figure 1 

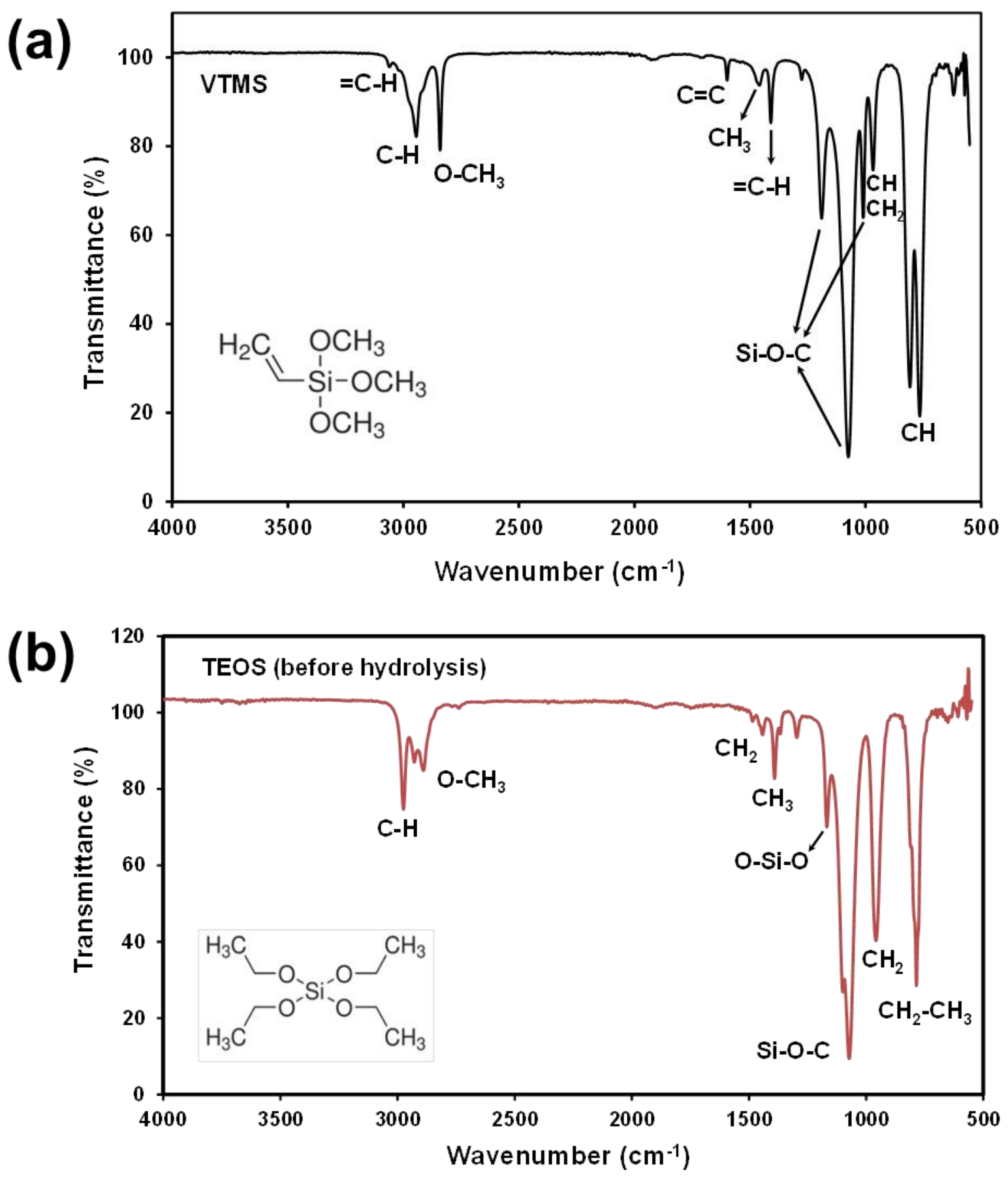

Figure 2 (a-b) 

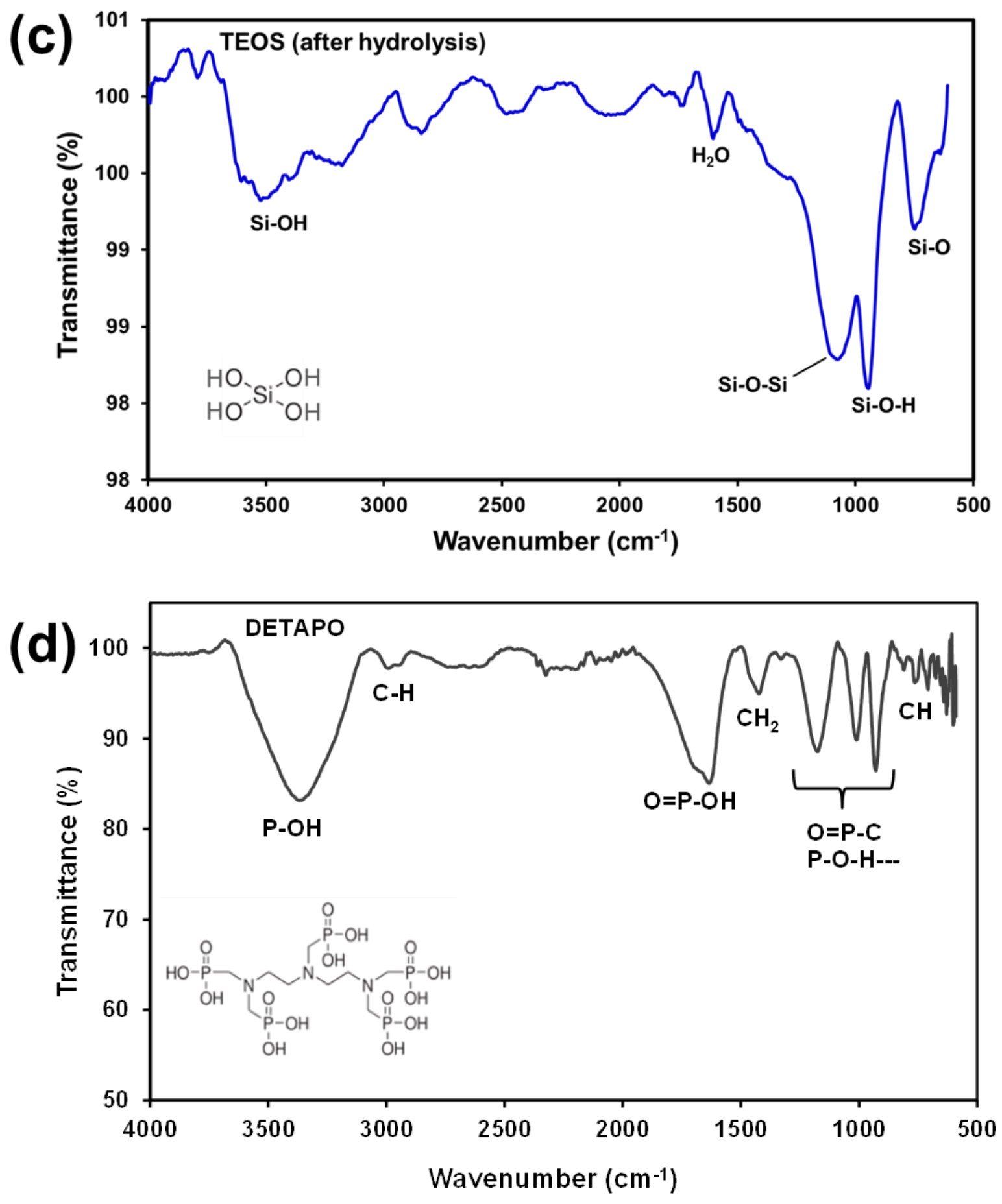

Figure 2 (c-d) 


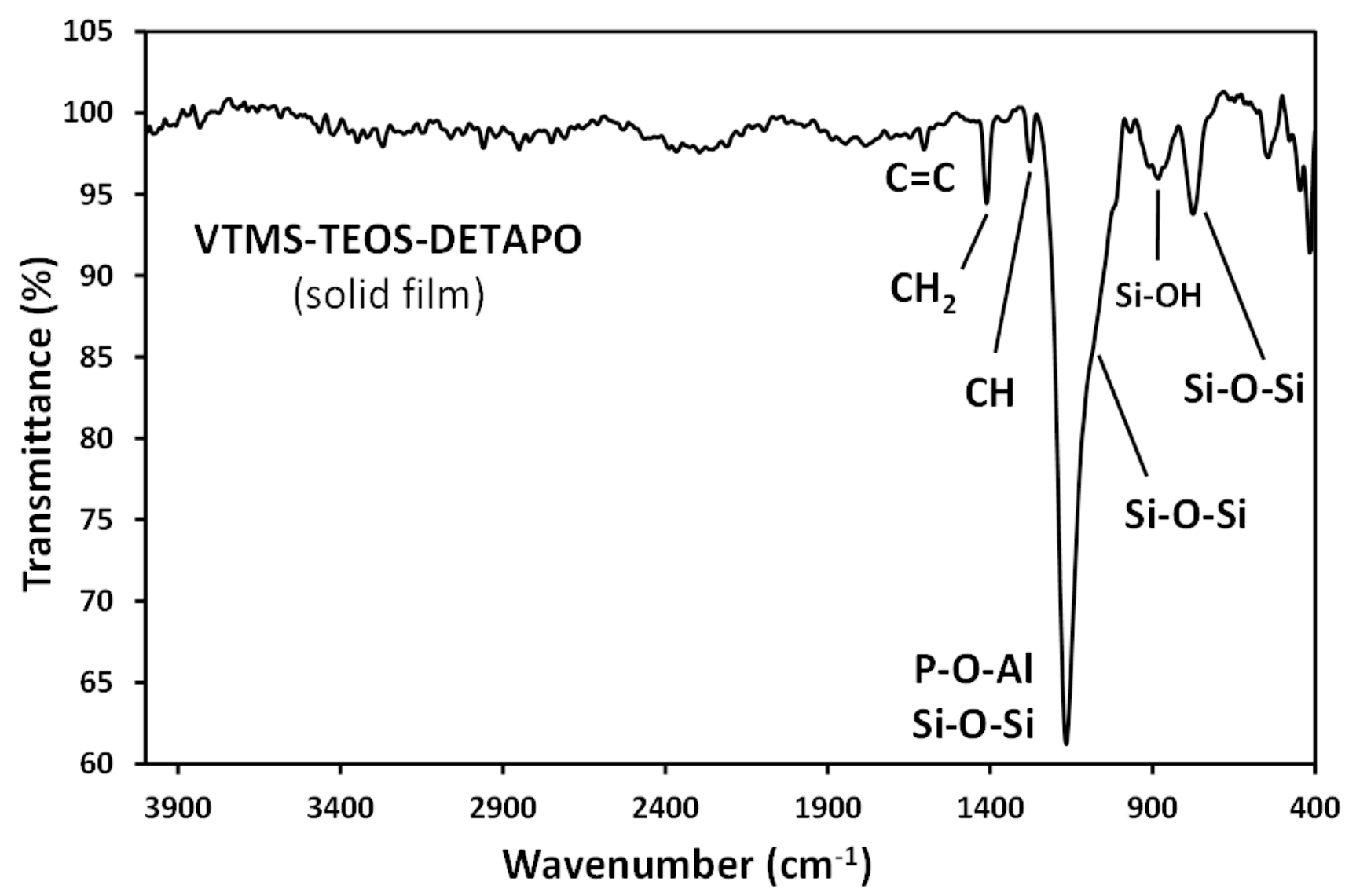

Figure 3 

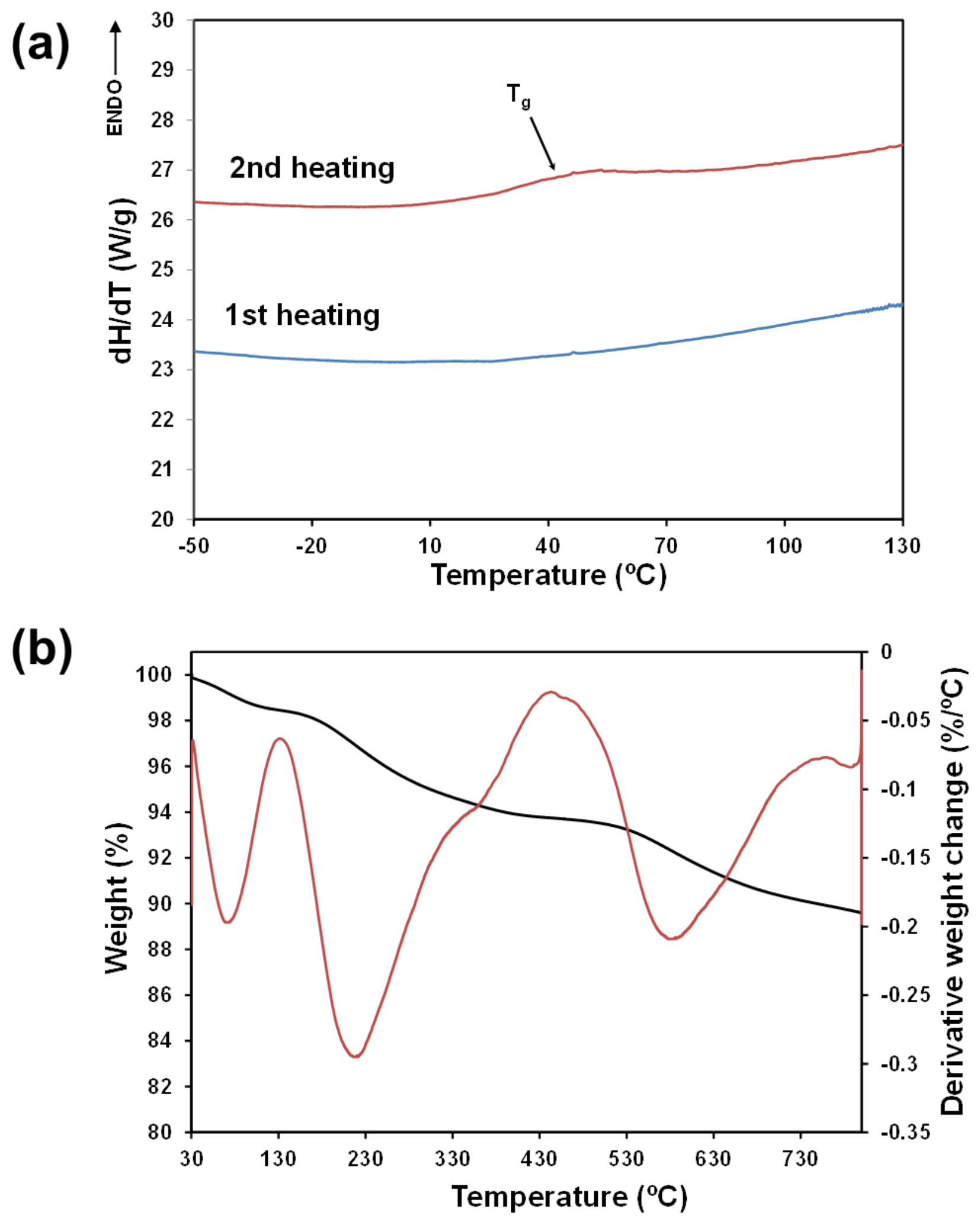

Figure 4 


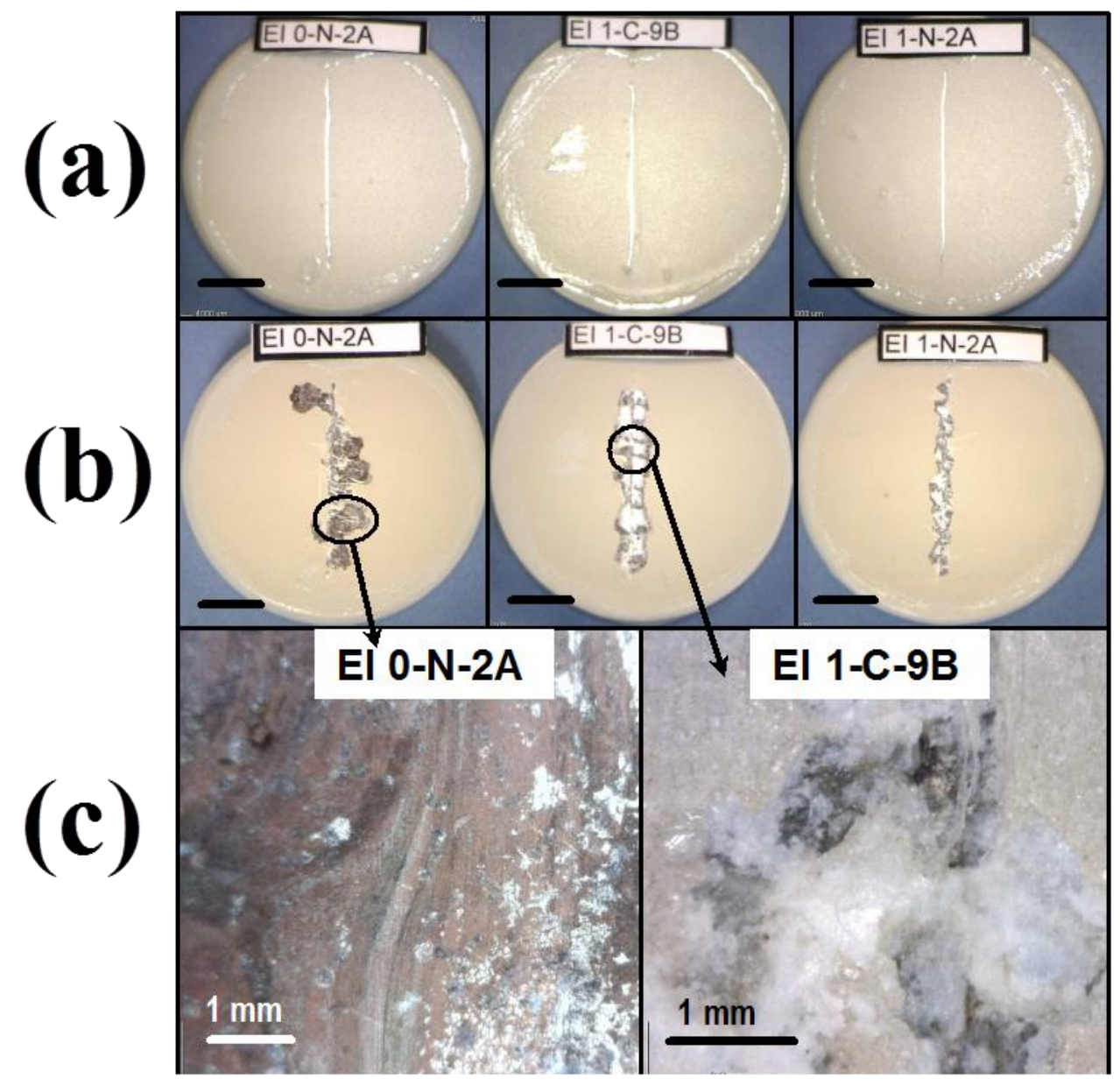

Figure 5 

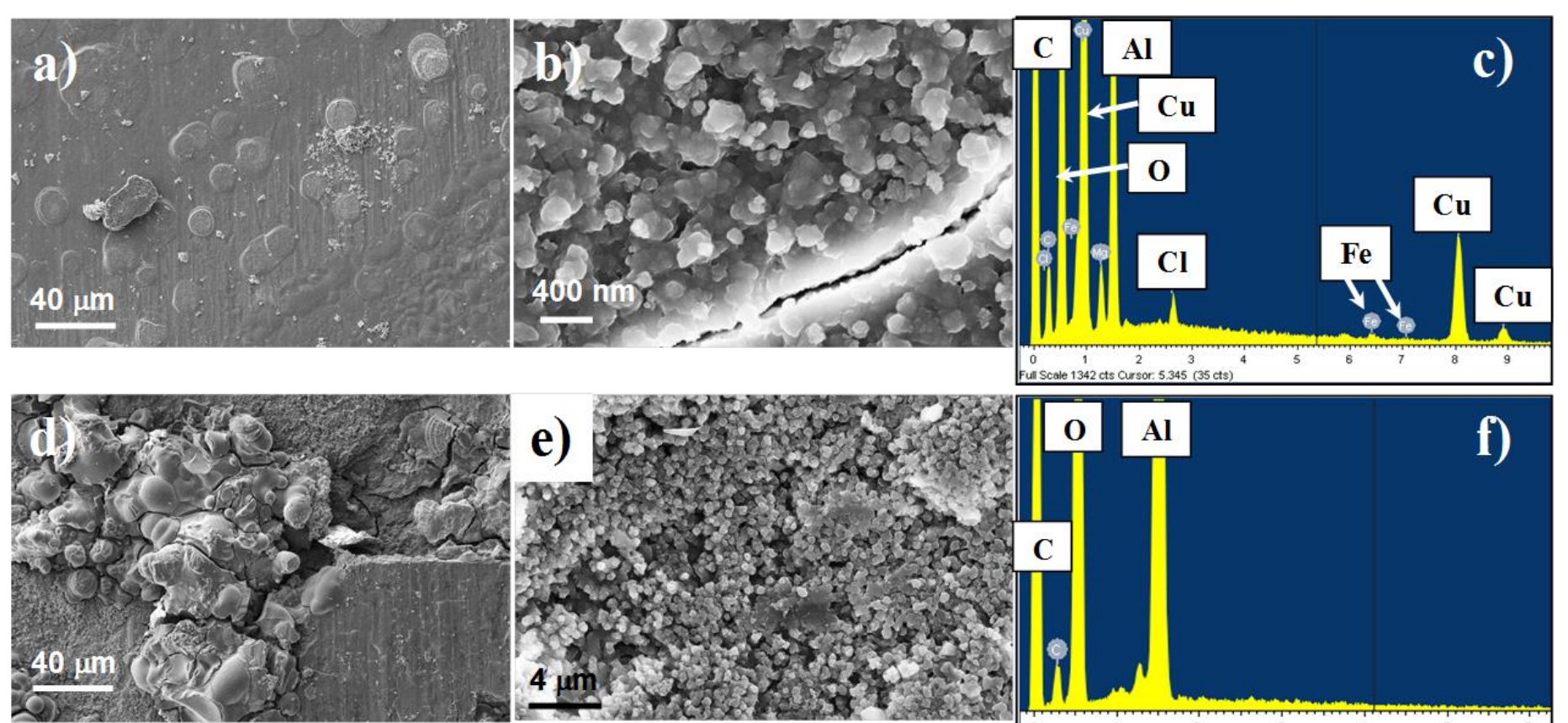

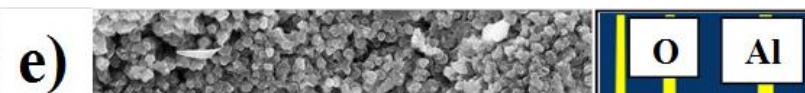
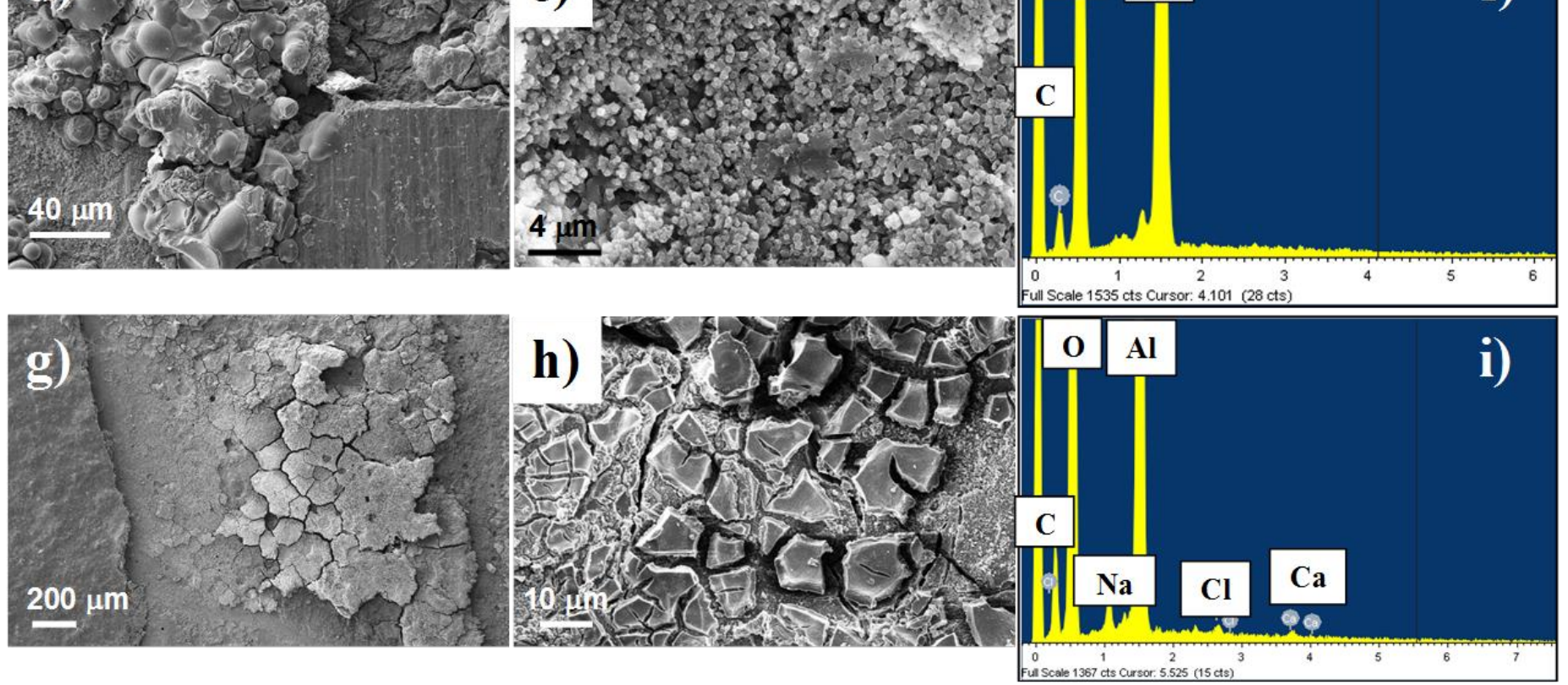

Figure 7 

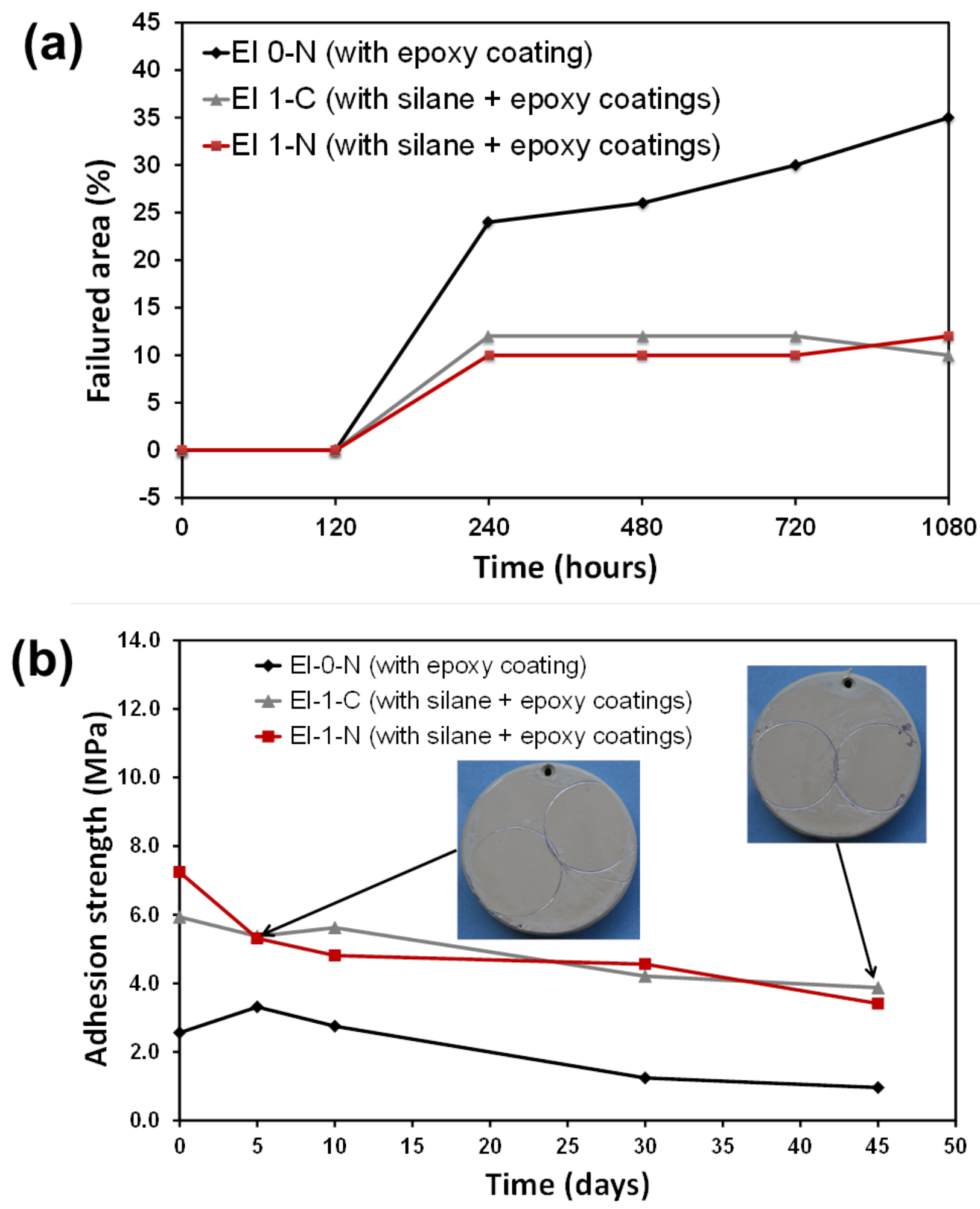

Figure 8 